\title{
Application of r-GO-MMT Hybrid Nanofillers for Improving Strength and Flame Retardancy of Epoxy/Glass Fibre Composites
}

\author{
Vijayananth Kavimani $\left(\mathbb{D},{ }^{1}\right.$ Balasubramaniam Stalin $\mathbb{D D}^{2}$ \\ Pudhupalayam Muthukutti Gopal $\mathbb{D}^{1},{ }^{1}$ Manickam Ravichandran $\mathbb{D}^{3},{ }^{3}$ Alagar Karthick $\mathbb{D}^{4}$, \\ and Murugesan Bharani $\mathbb{D}^{5}$ \\ ${ }^{1}$ Department of Mechanical Engineering, Karpagam Academy of Higher Education, Coimbatore, 641021 Tamilnadu, India \\ ${ }^{2}$ Department of Mechanical Engineering, Anna University, Regional Campus Madurai, Madurai, 625019 Tamilnadu, India \\ ${ }^{3}$ Department of Mechanical Engineering, K.Ramakrishnan College of Engineering, Tiruchirappalli, 621112 Tamilnadu, India \\ ${ }^{4}$ Department of Electrical and Electronics Engineering, KPR Institute of Engineering and Technology, Coimbatore, Tamilnadu, India \\ ${ }^{5}$ School of Textile Leather and Fashion Technology Kombolcha 208, Kombolcha Institute of Technology, Wollo University, \\ South Wollo, Ethiopia
}

Correspondence should be addressed to Murugesan Bharani; bharani.murugesan@kiot.edu.et

Received 24 December 2020; Revised 19 March 2021; Accepted 1 April 2021; Published 9 April 2021

Academic Editor: Sagar Roy

Copyright (C) 2021 Vijayananth Kavimani et al. This is an open access article distributed under the Creative Commons Attribution License, which permits unrestricted use, distribution, and reproduction in any medium, provided the original work is properly cited.

\begin{abstract}
The application of nanomaterials as a strengthening agent in the fabrication of polymer nanocomposites has gained significant attention due to distinctive properties which can be utilised in structural applications. In this study, reduced graphene oxide (r-GO) and montmorillonite (MMT) nanoclay were used as filler materials to fabricate hybrid epoxy-based nanocomposites. The synergistic effect of nanomaterials on flammability and mechanical behaviour of nanocomposites were studied. Results revealed that the addition of nanofiller showcases $97 \%$ and $44.5 \%$ improvement in tensile and flexural strength. However, an increment in the percentage of filler material over $0.3 \%$ exhibits a decremental mechanical property trend. Likewise, the addition of nanofiller increases the nonignition timing of the glass-fibre-reinforced epoxy composites. Fracture surface morphology displays the occurrence of the ductile fracture mechanism owing to the presence of hybrid fillers.
\end{abstract}

\section{Introduction}

In modern industries, epoxy-based resins are considered one of the most promising thermosetting polymers with outstanding merits, including low shrinkage, better adhesion, admirable chemical stability, and corrosion resistance [1-4]. These facts made them a candidate material to employ widely as coating materials, laminates, microelectronic materials, and aerospace materials [5-9]. Nevertheless, similar to other polymer resins, its extreme flammable nature and lower mechanical strength act as the potential barriers to limiting its prevalent applications. Consequently, it is authoritative to form a high strength and flame retarded epoxy resin to expand its future applica- tions among the areas that demand outstanding mechanical properties and flame retardancy. Composite fabrication is considered one way to improve the basic and functional properties of epoxy by adding suitable reinforcements and filler material [10-14]. Herein, glass fibres are commonly used as reinforcements to improvise polymer materials' basic strength and performance. Glass-fibre-reinforced polymers (GFP) have been practised in several industrial applications that include transport and electrical appliances with better mechanical properties [15-18].

Nevertheless, the inherent flammability of epoxy-based matrix induces potential fire hazard for GFP products. It brings large concern in enlightening the flame retardancy of GFP. Flame retardancy of GFP can be improved by various 
techniques such as retardant coating and charring method $[19,20]$. Several researchers used inorganic and organic retardants to decrease the flammability of epoxy. In recent halogen and non-halogen-based flame retardant materials, it is combined with epoxy resin to increase its flame retardant properties. However, the usage of halogen-based retardants results in the formation of harmful toxic gases that results in environmental pollution. To overcome these effects, halogen-free elements such as silicon and boron and some nanocarbon materials, hydroxides, and clays are used. In some research, hybrid fillers with different sizes and shapes are used to enhance the thermal properties of epoxy-based polymers by simplifying the development of compacted and effective heat transfer network [21-24].

Montmorillonite (MMT), a form of clay with various sodium and calcium ions, has more attraction in use as flame retardant filler material in polymer matrix composite due to its low cost. MMT can act dual role viz. shielding and insulating in the improvement of desirable properties of polymer matrix material [25-28]. It further assists in decreasing the smoke and formation of toxic gases during combustion. However, MMT has only minimal ability to increase the expected limiting oxygen index. Hence, there is a need to use additional filler material to make the epoxy-based resin pass in the flammability test. Nanomaterials such as graphene and carbon nanotubes are considered better filler materials to improve the flame retardancy of epoxy-based resins. Usage of nanofiller needs suitable dispersion in loading level to achieve the expected properties [29-34]. Graphene and its derives viz. graphene oxide, graphene nanoplates, and graphene nanosheet consisting of a carbon atom with lattice structure have been broadly applied in various multidisciplinary domains owing to its better electrical, thermal, and mechanical properties. Graphene derivates work as an inhibiting barrier over char residues in the condensed phase and restraining its volatiles. Graphene oxide (GO) is broadly employed as a modified substrate due to its carbon-layered structures [35-38]. Incorporating favourable functional groups in a graphene oxide sheet is also considered an effective way to improve the desired properties of polymer while using it as filler material. To improve polymer composites' thermal behaviour, synergistic effect strategies are considered a feasible approach to resolve interface and dispersion-based issues in developing polymer composite. Herein, easily dispersed nanocarbon materials like graphene and CNT are used in property enhancements [39-41]. There are few kinds of research in which MMT and graphene derivatives are used as filler material to increase the mechanical and flame retardancy characteristics. He and coworkers used MMT-based hybrid filler material to improve the flame retardancy behaviour of epoxy matrix. Results reveal that hybrid nanofiller usage increases the limiting oxygen index of epoxy and attained V0 rating in the flammability test [42]. Kim et al. used MMT to develop basalt fibre-reinforced composite and observed that the addition of MMT improves the interfacial interaction between the matrix and reinforcement.

Further, it was observed that the saline treatment in composite exhibits $33 \%$ decrement in fatigue strength [43]. Souza and coworkers utilised MMT as filler material to improve the thermomechanical behaviour of epoxy resin. The results indicate that MMT's addition influences the delamination and uniformity of matrix, and addition of MMT up to $3 \mathrm{wt}$ \% showcases betterment in dynamic mechanical properties [44]. Kamar and coworkers investigated the effect of graphene nanoplatelets over epoxy matrix. Their observation depicts that incorporating $0.25 \mathrm{wt}$ \% of graphene nanoplatelets improves the flexural strength of matrix up to $29 \%$, and $25 \%$ improvement in fracture toughness is also observed [45]. Naeem and coworkers developed a graphene-based composite and investigated its dynamic thermomechanical properties. Results revealed that the addition of graphene increases the fracture toughness and stiffness of matrix material up to $78.41 \%$ and $16.29 \%$. Usage of graphene up to 0.25 vol.\% improves its glass transition temperature [46]. Based on a clear-cut literature survey, the addition of graphene and MMT improvises the basic and functional properties of the polymer. However, there is limited research in the investigation on the effect of hybrid MMT-graphene fillers in the epoxy composite. Hence, this research focuses on developing MMT-graphene hybrid filler-based composites and examining their mechanical and flame retardancy behaviours.

\section{Materials and Methods}

The polymer matrix used for developing the novel composite is epoxy resin diglycidyl ether of bisphenol A grade LY 556 with the hardener of $\mathrm{HY} 951$ grade $\left(\mathrm{C}_{6} \mathrm{H}_{18} \mathrm{~N}_{4}\right)$, which has the gel time of 2 to $3 \mathrm{~h}$. Smaller viscosity array, fibre impregnations, and outstanding dimensional steadiness are the key factors that lead to the selection of the material above as matrix. In improving the mechanical properties of the matrix material, 200 GSM glass fibre is utilised as a reinforcement. The percentage of glass fibre reinforcement is fixed as 30\% based on the literature where the composites with $30 \%$ glass fibre addition yielded better properties. The nanofiller materials used in this research are reduced graphene oxide (r-GO) and MMT nanoclay, where the amount of MMT is fixed as $1.5 \%$ and the graphene percentage is varied from 0.1 to 0.4 with an equal interval of $0.1 \%$. Herein, $r-G O$ is synthesised through the modified Hummers method, and detailed r-GO synthesis procedure was already reported in previous works [45]. MMT is received from Ad-Nano Technologies Private Limited with the average size of 50-100 nm with alumina silicate layers of $1 \mathrm{~nm}$ thickness. XRD of as purchased MMT is depicted in Figure 1, and the purchased MMT is used directly without any modification.

2.1. Composite Fabrication. The fabrication methodology followed to fabricate the nanofiller-added glass-fibrereinforced polymer matrix composite is the simple and low-cost fabrication method process, namely, compression moulding. The measured amount of nanofillers, namely, $r$ GO and MNT, as per the research hypothesis, is mixed with ethanol and ultrasonicated for an hour and mixed with the matrix resin. The matrix material mixed with nanofillers is stirred mechanically at $1200 \mathrm{rpm}$ for two hours because of attaining uniform distribution of fillers in the matrix. 


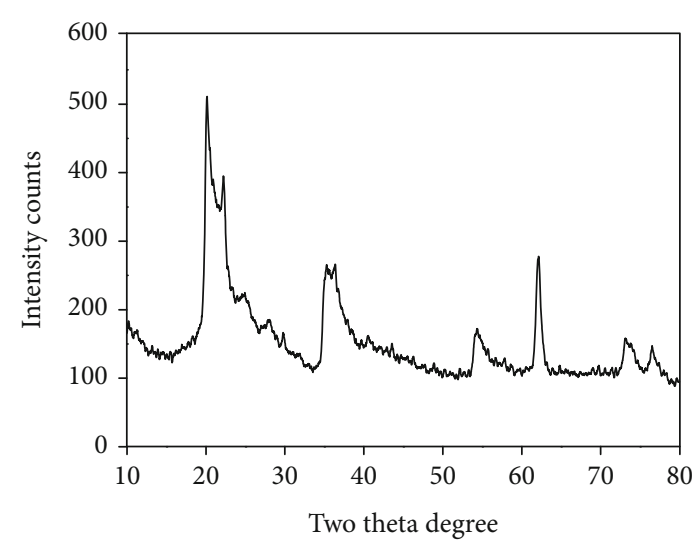

FIGURE 1: XRD of as received montmorillonite nanoclay.

Subsequently, a hardener (HY951) is added in a $1: 10$ ratio, and mixing is done for 5 minutes. The prepared mixture is then coated over the glass fibre (both sides) initially through the hand layup method. Process variables and their operating range for composite fabrication are fixed based on the trial and error method. Stacking is done in the flat mould of 270 $\times 270 \times 30 \mathrm{~mm}$ size, where the number of coated glass fibre layer is ten followed by degassing. Then, the stackings were hot-pressed under the pressure of $15 \mathrm{MPa}$ and allowed to cure. Other nanofiller-added epoxy-glass fibre composites were prepared with various r-GO filler percentage viz by following the same procedure, $0.1,0.2,0.3$, and 0.4 .

2.2. Material Characterisation. X-ray diffractometer (BRUKER) was utilised to authorise the presence of graphene oxide and MMT. Fourier transform infrared spectroscopy (FTIR) was used to confirm functional groups' presence in the developed composite. ASTM D 638 standard was adopted to understand the tensile behaviour of the developed composite. ASTM D 790 standard is used to find the flexural strength of the fabricated composite. In contrast, ASTM D 256 standard is adapted to understand the impact strength behaviour by using a Charpy impact testing machine with a sample dimension of $65 \times 13 \times 3 \mathrm{~mm}$. Experiments were repeated four times, and the average value is noted for the exactness of the attained results. Scanning electron microscopy (JEOL JSM6610LV) is used for fracture surface analysis. The UL-94 vertical burning test is accompanied by adopting ASTM D3801 standard to analyse the flammability nature, and tests were conducted over five samples, and the average values are noted. A limiting oxygen test was conducted on developed samples based on ASTM D2863.

\section{Results and Discussion}

3.1. XRD and FTIR of the Developed Composite. XRD and FTIR analysis results of the developed composites are depicted in Figures 2(a) and 2(b), which confirm the presence of $\mathrm{r}-\mathrm{GO}$ and MMT in the epoxy matrix. The peak near $25.4^{\circ}$ is respective to 111 planes, and small peaks near $43.6^{\circ}$ are related to 002 planes of graphene, and other minor peaks are respective peaks of MMT and base matrix (Figure 2(a)). The diffraction peaks at $19.8^{\circ}$ and $20.9^{\circ}$ are the related peaks of MMT with 100 planes, and the attained peaks are matched with JCPDS no. 13-0135. Figure 2(b) depicts the presence of functional groups and their state of vibration in the developed composite. The absorption peaks near $3395 \mathrm{~cm}^{-1}$ reveal $\mathrm{O}-\mathrm{H}$ stretching vibration, peaks near $1652 \mathrm{~cm}^{-1}$ associated with $\mathrm{C}=\mathrm{N}$ bonds, and peaks near $1387 \mathrm{~cm}^{-1}$ related to $\mathrm{C}=\mathrm{C}$ stretching vibration. Minor peak near $1738 \mathrm{~cm}^{-1}$ belongs to the $\mathrm{COOH}$ group. Absorption peaks near $3618 \mathrm{~cm}^{-1}$ related to $\mathrm{Al}-\mathrm{O}-\mathrm{H}$ stretching vibrations of MMT and smaller peaks at the range of $1089-1035 \mathrm{~cm}^{-1}$ are correlated peaks of Si$\mathrm{O}-\mathrm{Si}$ stretching vibrations. Likewise, a peak near $1625 \mathrm{~cm}^{-1}$ represents the bending vibration of the $\mathrm{H}-\mathrm{O}-\mathrm{H}$ group and the absorption peak around $1030 \mathrm{~cm}^{-1}$ was associated with stretching vibration of $\mathrm{Si}-\mathrm{O}-\mathrm{Si}[47-50]$.

3.2. Tensile Behaviour of Developed Composite. Stress-strain curves and tensile behaviour of the developed nanofilleradded composites are given in Figures 3(a) and 3(b). It is evident from the figure that the added r-GO and MMT have a greater influence on the epoxy-glass fibre composites' tensile behaviour. Tensile modulus and strength are increased significantly with the addition of nanofillers.

The addition of $\mathrm{r}-\mathrm{GO}$ resulted in increased tensile modulus from $1.2 \mathrm{GPa}$ to $2.2 \mathrm{GPa}$, where sudden improvement is found while adding $0.1 \% \mathrm{r}-\mathrm{GO}$. It increases gradually for further addition of r-GO. On the other hand, the tensile strength increased up to $150 \mathrm{MPa}$ for $0.3 \% \mathrm{r}-\mathrm{GO}$ addition, and it decreased by $0.4 \% \mathrm{r}-\mathrm{GO}$ addition. This improvement in tensile modulus and strength can be attributed to the nanofillers' restriction for polymer chain mobility. Higher-strength, modulus, and aspect ratio and healthier interfacial bond among the nanofiller and matrix are also the key factors that contributed to the enhancement of tensile properties. The decrease in tensile strength for the $0.4 \%$ rGO-added composite might be attributed to the agglomeration and void formation tendency of nanoparticles when reinforced in higher quantity [28].

3.3. Flexural Strength of Developed Composite. Stress-strain curves and flexural strength of the developed composites are depicted in Figures 4(a) and 4(b). It indicates that the flexural properties of the epoxy-glass fibre composites increase up to $0.3 \% \mathrm{r}-\mathrm{GO}$ addition, and further addition of r-GO resulted in decreased properties. Flexural strength and modulus of the composite increase gradually up to $0.3 \%$ of $\mathrm{r}-\mathrm{GO}$ addition, and small decrement is observed for further $\mathrm{r}-\mathrm{GO}$ addition. This enhancement in flexural properties is due to two possible mechanisms, enhancement in the strength of the matrix due to modification due to added $r$ $\mathrm{GO}$ and better interfacial bonding.

To withstand higher loads, the load transmission from the matrix to reinforcement should be as high as possible. This increment in strength of the matrix mainly depends on the interfacial area between the matrix and r-Go. As the reinforced $\mathrm{r}-\mathrm{GO}$ and $\mathrm{MNT}$ are in nanosize, they are having a high surface area which resulted in a higher interfacial area between the matric and nanofillers. This higher interfacial 


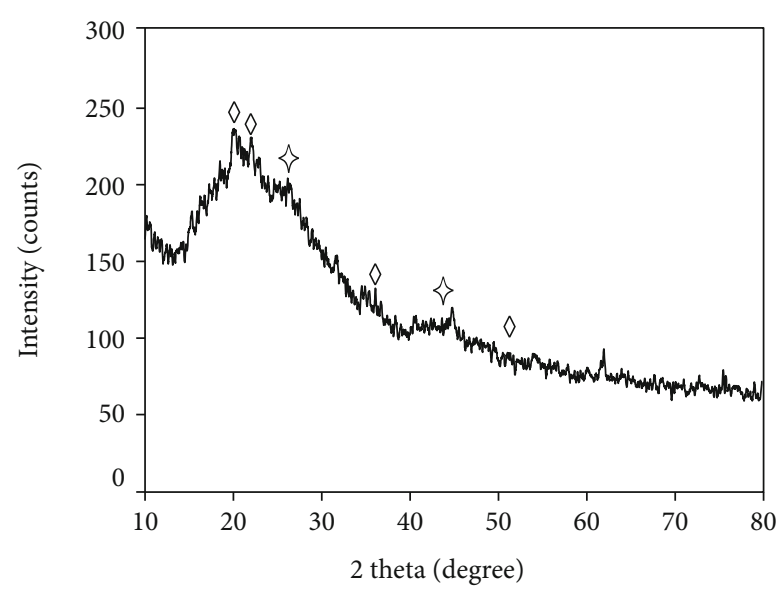

$\diamond$ MMT

$\diamond \mathrm{r}-\mathrm{GO}$

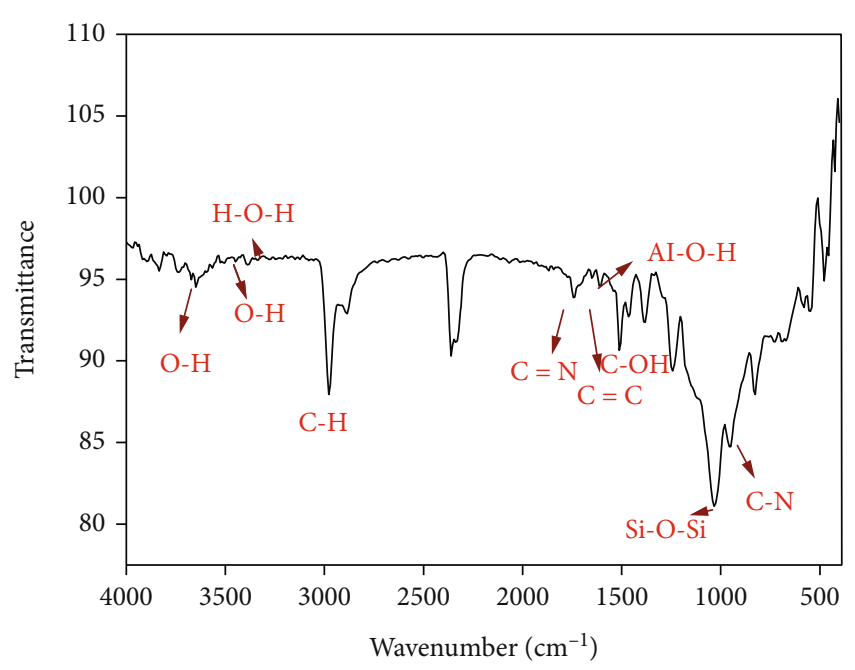

(b)

FIGURE 2: Epoxy-r-GO-MMT composite: (a) XRD; (b) FTIR.

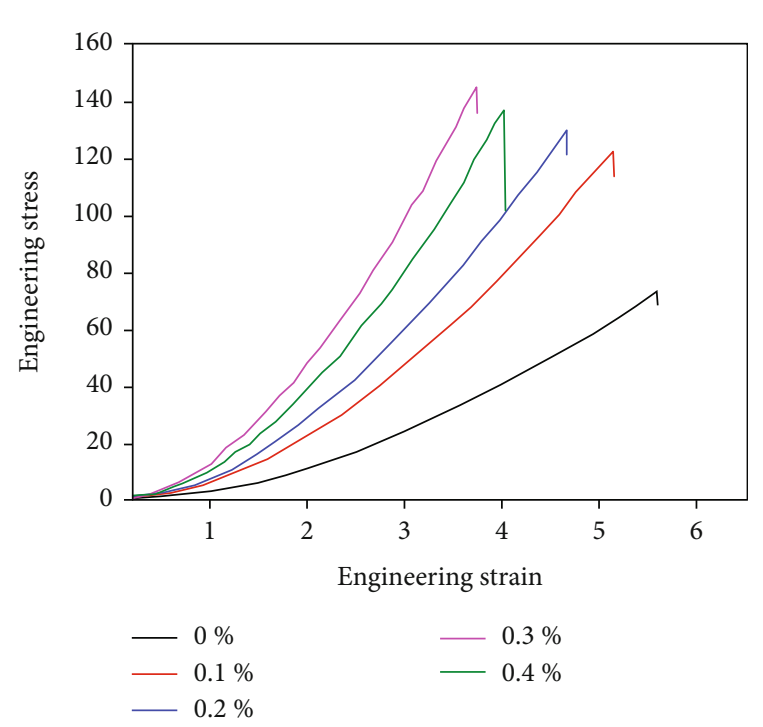

(a)

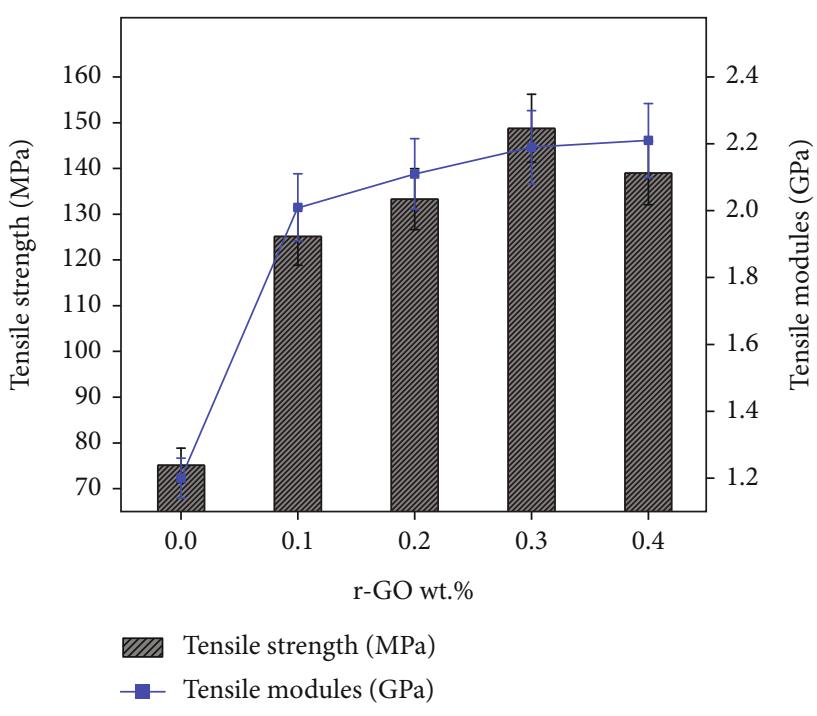

(b)

FIgURE 3: $(\mathrm{a}, \mathrm{b})$ Variation of tensile strength with respect to $\mathrm{r}-\mathrm{GO}$ addition.

area enables more stress transfer among them which facilitates the polymer composites to bear more stress, i.e., strength increases. In addition to this, generally, the nanofiller-added polymers possess better strength than the raw polymers as a result of physical absorption of polymer onto the surface of added nanofiller. When higher amount of $\mathrm{r}$-GO is added with the matrix, there are possibilities of particle agglomeration owing to the higher surface area. This particle agglomeration decreases the effective surface area of the nanofillers which results in decreased load-bearing capability of the composites [51].
3.4. Impact Strength of Developed Composite. The impact strength of the developed composites, i.e., the capability of absorbing energy, is illustrated in Figure 5. It is evident from the depiction that the addition of $\mathrm{r}-\mathrm{GO}$ improves the composites' energy absorption capability up to $0.3 \%$ addition. The process where the energy is absorbed during sudden loading of polymer composites is matrix deformation, interface debonding, and reinforcement fracture. Among these phenomena, which absorbs lower energy is said to be the key factor for fracture. However, the crack length during fracture is high in the case of particulate-reinforced 


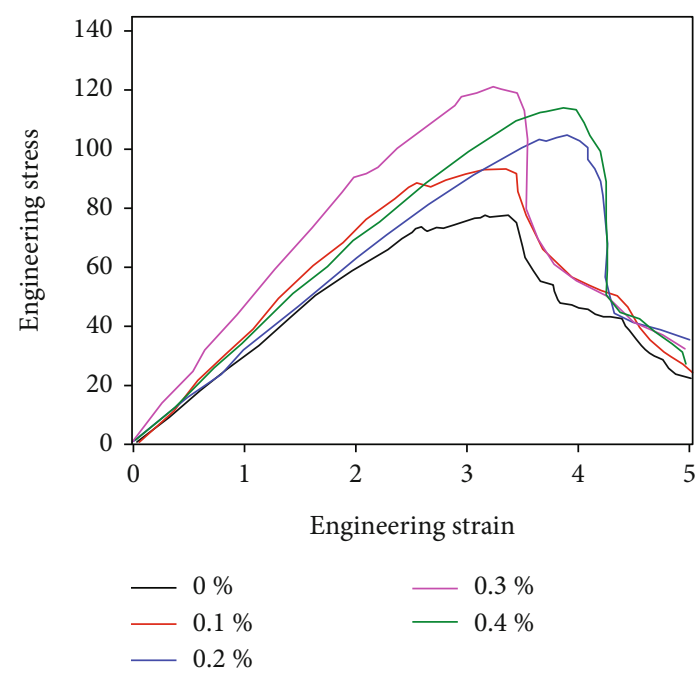

(a)

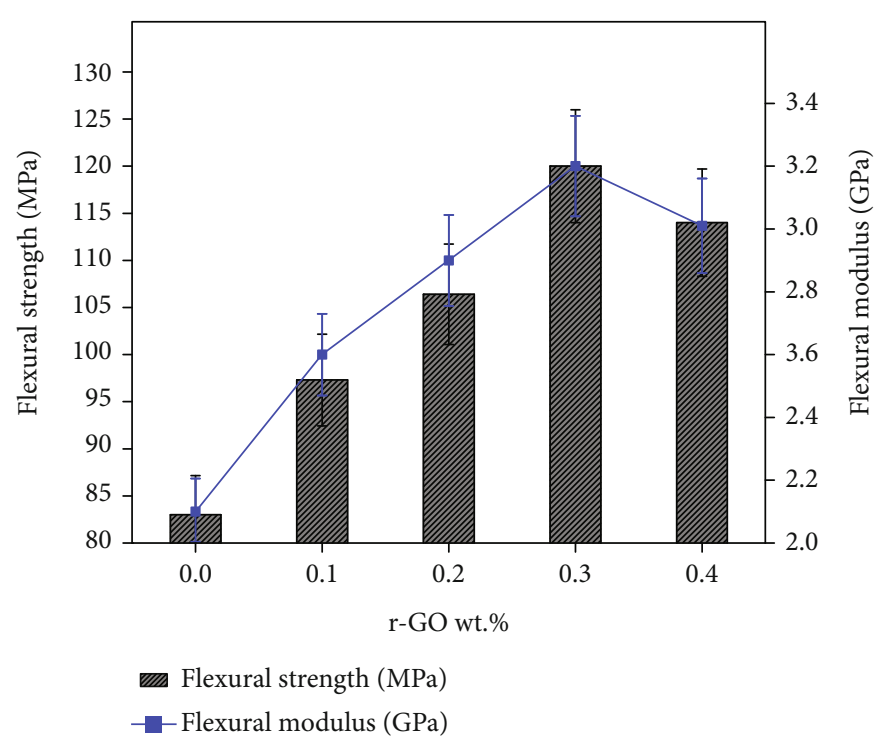

(b)

Figure 4: (a, b) Variation of flexural strength with respect to r-GO addition.

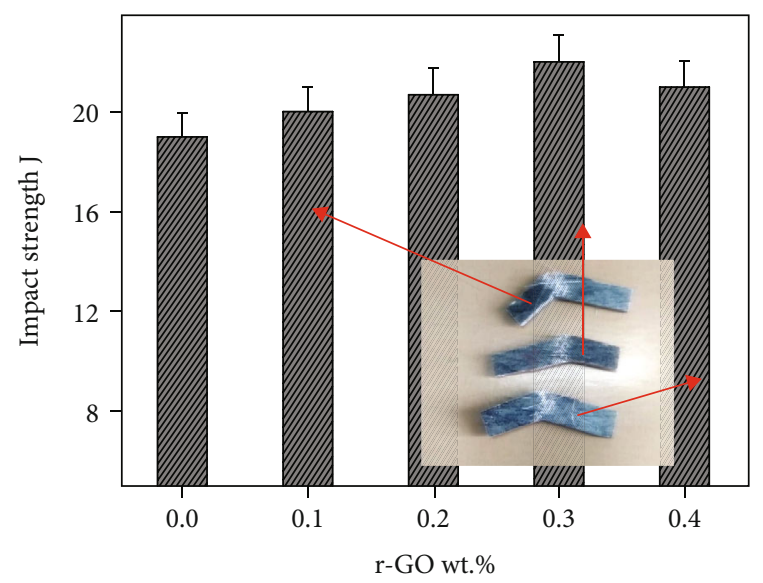

FIGURE 5: Variation of impact strength with respect to $r$-GO addition.

polymers. Since the reinforcing fillers are nano in size, their surface area is also high, leading to an increase in crack length, i.e., more energy absorbed. These reinforced fillers restrict the advancing cracks and branch the cracks that lead to more energy absorption.

3.5. Fracture Surface Morphology of the Developed Composite. The fractography of the developed composites subjected to the tensile test is shown in Figures 6(a)-6(d) that aids to analyse the mechanism of failure. The fracture surface micrographs illustrated in Figures 6(a) and 6(b) belong to the unfilled composite material, i.e., the composite without hybrid nanofillers clearly shows the matrix and fibre debonding. This debonding of fibre from the epoxy matrix due to the lack of interfacial bonding leads to failure of composite material when subjected to smaller loads, i.e., the composite exhibits lesser strength. Huge fibre pull out, as depicted in Figures 6(a) and 6(b), occurs due to inadequate fibre matrix bonding and subsequently effortless fracture. The fractured surface of $0.2 \mathrm{wt} . \%$ of r-GO-added epoxyglass fibre-MMT composite is given in Figure 6(c), which also has the composite EDS spectrum.

The EDS spectrum of the composite endorses the $r$ GO and MMT nanofillers' existence, and Figure 6(d) depicts the fractured surface of the 0.3 wt. $\%$ of r-GO added epoxy-glass fibre-MMT composite. It is clearly evident from Figures 6(c) and 6(d) that the addition of nanofillers highly influences the adhesion of fibre with epoxy matrix. Better adhesion among the epoxy matrix and glass fibre can be easily visualised from Figures 6(c) and 6(d). It is visible from Figures $6(\mathrm{c})$ and $6(\mathrm{~d})$ that the matrix material and fillers are sticking with fibres which are attributed to the improvement in strength for the filler-added composite when compared to composite without filler.

Conversely, only minimal matrix material is stick with fibre for unfilled composite shown in Figure 6(b) and complete debonding of fibre from the matrix is evident from Figure 6(a). When the load is applied over the composite material, a crack is formed initially and it has to propagate across a huge number of nanofillers and fibre matrix interface which act as a hindrance to the crack propagation. As a result of these hindrances offered by the fillers and interface, the crack propagation changes the direction several times, increasing crack length, which results in improved strength. The fillers that hinder the crack propagation have to be fractured, which also required additional load, i.e., strength increases. So the improvement in strength is achieved with the addition of r-GO and MNT nanofillers with the epoxyglass fibre composites [30-33]. 


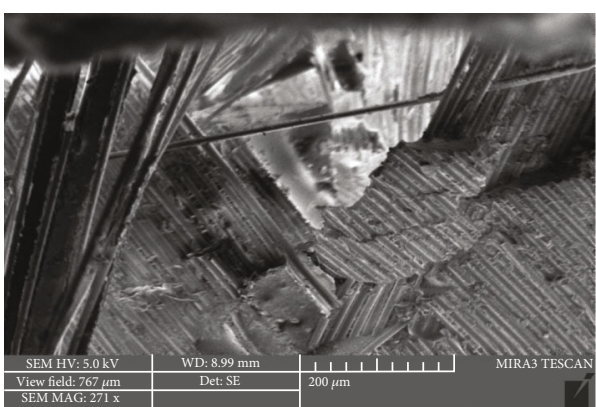

(a)

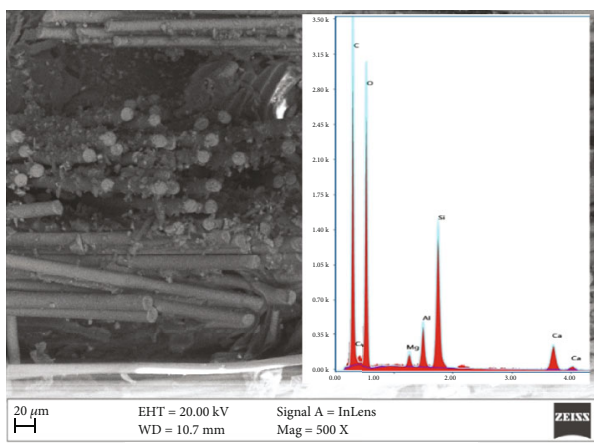

(c)

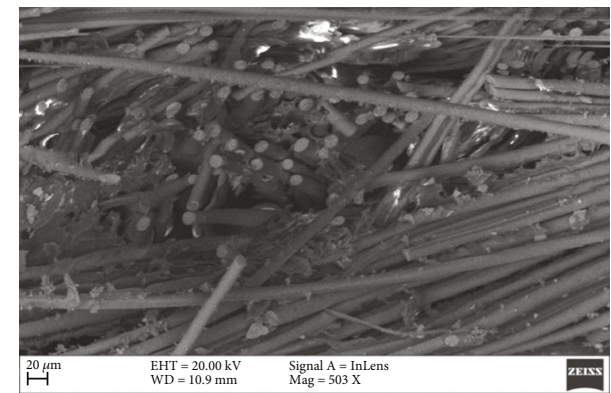

(b)

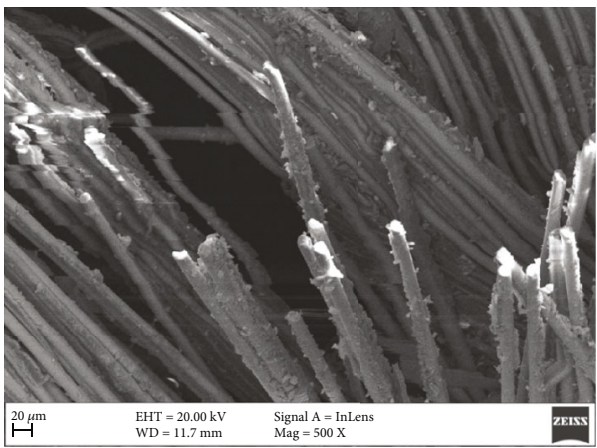

(d)

Figure 6: Fracture surface of composite with (a, b) 0 wt.\% filler, (c) 0.2 wt.\% of r-GO, and (d) 0.3 wt.\% of r-GO.

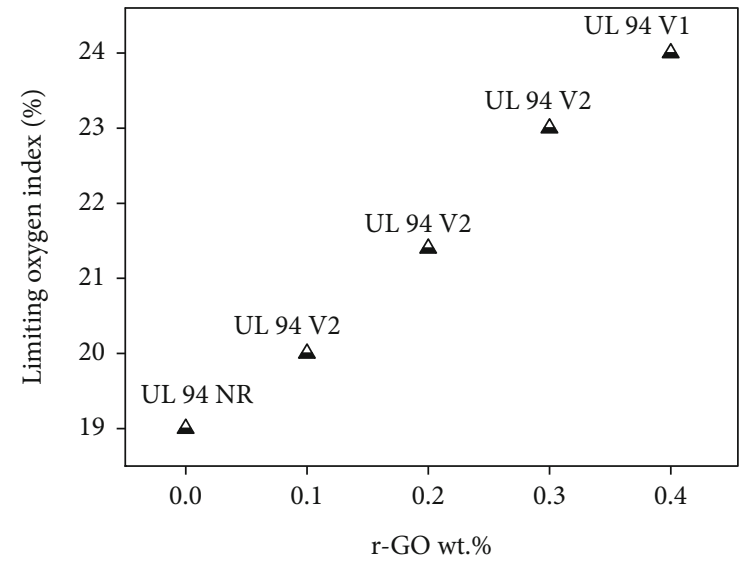

Figure 7: Limiting oxygen index and vertical flammability ranking of composites.

3.6. Fire Retardancy Behaviour of Developed Composite. The limiting oxygen index and UL 94 rating are depicted in Figure 7. Herein, UL 94 ratings are given based on the selfsustained burning duration. Based on the available literature, burning time less than 10 seconds is termed as V0 rating and the material is considered the best for flame retardant applications. V1 ratings are given to the sample with a burning time of fewer than 30 seconds, and burning is not sustained. $\mathrm{V} 2$ rating is given to the samples with burning seconds of 30 , and burning is not sustained, but flaming drips ignite the cotton below the specimen. NR rating is given to the samples which have more than 30 seconds of burning. The limiting oxygen index value is an important pointer on polymer and plastic materials' flammability as in general, materials with higher limiting oxygen index are considered the flameretardant material. The limiting oxygen index is defined as the volume percentage of minimum oxygen consideration that assists in material combustion. It can be notified from Figure 7 that the addition of nanofillers showcases better influence in the limiting oxygen index of epoxy polymer matrix composite. In this, the addition of $0.4 \mathrm{wt} . \%$ of $\mathrm{r}-\mathrm{GO}$ improves the limiting oxygen index values up to $\sim 26.32 \%$ and $\sim 21.01 \%$ of improved limiting oxygen index values was attained for $0.3 \mathrm{wt}$. $\%$ of r-GO filler. It can also be noted that matrix material has a low limiting oxygen index, indicating the poor flammability resistance of the epoxy polymer. It can also be observed that the addition of $\mathrm{r}$-GO showcases excellent performance on the developed composite's flame retardant behaviour. This might be due to the effect of intermolecular and intramolecular interaction among the matrix and filler phase.

During testing conditions, the presence of $\mathrm{r}-\mathrm{GO}$ fillers helps in limiting the rapid burning of composite in thermal condensation of functional groups present in composite structures. The presence of hybrid filler forms as a passive barrier over the burning surfaces that hinders the proclamation of noncombustible gases and further limits the destruction of dripping properties of the composite. It can be notified that the increase also of hybrid filler reduces the burning timing of advanced composite. The samples with higher $\mathrm{r}-\mathrm{GO}$ wt.\% have $\mathrm{V} 1$ rating in vertical flammability testing, and it depicts that increasing in $\mathrm{r}-\mathrm{GO}$ improves the flame-retardant performance of the developed composite. V2 rating is attained for the composites 
made with $0.3,0.2$, and $0.1 \mathrm{wt} . \%$ of $\mathrm{r}-\mathrm{GO}$; this might be due to the insufficient supply of filler material that reduces the burning process. The matrix material has an NR rating that means the samples have burned more than 30 seconds or burned completely [52-55].

\section{Conclusions}

Reduced graphene oxide and MMT are used as filler material in epoxy-based glass fibre composites to improve mechanical and flame retardancy properties. The results observed from the various characteristic studies conducted are as follows:

(i) Addition of $0.3 \mathrm{wt} . \%$ of r-GO improves the tensile strength up to $\sim 97 \%$

(ii) Addition of r-GO results in $44.5 \%$ improvement of the flexural strength and $15.6 \%$ impact behaviour of composite

(iii) V1 rating was attained for $0.4 \mathrm{wt} . \% \mathrm{r}$-GO incorporated samples, and a decrease in $\mathrm{r}-\mathrm{GO}$ reduces $\mathrm{UL}$ 95 rating

(iv) These composites may be suggested in potential applications like roofing sheet and car dashboards

\section{Data Availability}

The data used to support the findings of this study are included in the article.

\section{Conflicts of Interest}

The authors declare that there is no conflict of interest regarding the publication of this article.

\section{References}

[1] N. M. Kumar, M. Samykano, and A. Karthick, "Energy loss analysis of a large scale BIPV system for university buildings in tropical weather conditions: a partial and cumulative performance ratio approach," Case Studies in Thermal Engineering, vol. 25, article 100916, 2021.

[2] V. Chandran, C. K. Patil, A. Karthick, D. Ganeshaperumal, R. Rahim, and A. Ghosh, "State of charge estimation of lithium-ion battery for electric vehicles using machine learning algorithms," World Electric Vehicle Journal, vol. 12, no. 1, p. 38, 2021.

[3] V. S. Chandrika, A. Karthick, N. M. Kumar, P. M. Kumar, B. Stalin, and M. Ravichandran, "Experimental analysis of solar concrete collector for residential buildings," International Journal of Green Energy, vol. 18, no. 6, pp. 615-623, 2021.

[4] C. Sowmya Dhanalakshmi, P. Madhu, A. Karthick, and R. Vigneshkumar, "Combination of woody and grass type biomass : waste management, influence of process parameters, yield of bio-oil by pyrolysis and its chromatographic characterization," vol. 80, pp. 172-180, 2021.

[5] M. R. Zakaria, H. Md Akil, M. F. Omar, M. H. Abdul Kudus, F. N. A. Mohd Sabri, and M. M. A. B. Abdullah, "Enhancement of mechanical and thermal properties of carbon fiber epoxy composite laminates reinforced with carbon nanotubes interlayer using electrospray deposition," Composites Part C: Open Access, vol. 3, article 100075, 2020.

[6] N. Kadhim, A. Zaman, M. Jiang et al., "A cast-in-place fabrication of high performance epoxy composites cured in an in-situ synthesized 3D foam of nanofibers," Composites Part B, Engineering, vol. 205, article 108495, 2021.

[7] Y. Padarthi, S. Mohanta, J. Gupta, and S. Neogi, “Assessment of transport kinetics and chemo-mechanical properties of GF/epoxy composite under long term exposure to sulphuric acid," Polymer Degradation and Stability, vol. 183, article 109436, 2021.

[8] J. He, H. Wang, Q. Qu et al., "Construction of interconnected $\mathrm{SiC}$ particles attached rGO structure in epoxy composites to achieve significant thermal conductivity enhancement," Materials Today Communications, vol. 25, p. 101584, 2020.

[9] M. K. Pasupathi, K. Alagar, P. Michael Joseph Stalin, M. M. Matheswaran, and G. Aritra, "Characterization of hybridnano/paraffin organic phase change material for thermal energy storage applications in solar thermal systems," Energies, vol. 13 , no. 19 , p. $5079,2020$.

[10] M. Wang, L. Ma, B. Li et al., "One-step generation of silica particles onto graphene oxide sheets for superior mechanical properties of epoxy composite and scale application," Composites Communications, vol. 22, article 100514, 2020.

[11] A. Tamayo-Aguilar, M. V. Guamán, V. H. Guerrero et al., "Mechanical properties of amine-cured epoxy composites reinforced with pristine protonated titanate nanotubes," Journal of Materials Research and Technology, vol. 9, no. 6, pp. 15771-15778, 2020.

[12] N. B. Karthik Babu, T. Ramesh, and S. Muthukumaran, "Physical, tribological and viscoelastic behavior of machining wear debris powder reinforced epoxy composites," Journal of Cleaner Production, vol. 272, article 122786, 2020.

[13] M. Kim, H. Ko, and S.-M. Park, "Synergistic effects of aminemodified ammonium polyphosphate on curing behaviors and flame retardation properties of epoxy composites," Composites Part B, Engineering, vol. 170, pp. 19-30, 2019.

[14] S. D. Kumar, M. Ravichandran, A. Jeevika, B. Stalin, C. Kailasanathan, and A. Karthick, "Effect of $\mathrm{ZrB} 2$ on microstructural, mechanical and corrosion behaviour of aluminium (AA7178) alloy matrix composite prepared by the stir casting route," Ceramics International, vol. 47, no. 9, pp. 1295112962, 2021.

[15] V. K. Ramalingam, A. Karthick, M. P. V. Jeyalekshmi, A. M. M. A. J. Decruz, A. M. Manokar, and R. Sathyamurthy, "Enhancing the fresh water produced from inclined cover stepped absorber solar still using wick and energy storage materials," Environmental Science and Pollution Research, vol. 28, no. 14, pp. 18146-18162, 2021.

[16] M. E. H. Attia, Z. Driss, A. E. Kabeel, A. Afzal, A. M. Manokar, and R. Sathyamurthy, "Phosphate Bed as Energy Storage Materials for Augmentation of Conventional Solar Still Productivity," Environmental Progress \& Sustainable Energy, article e13581, 2021.

[17] S. K, K. Alagar, V. K. R, M. P. VJ, and M. P, "Performance and emission characteristics of diesel engine fueled with ternary blends of linseed and rubber seed oil biodiesel," Fuel, vol. 285, article 119255, 2021.

[18] V. S. Chandrika, M. M. Thalib, A. Karthick et al., "Performance assessment of free standing and building integrated grid connected photovoltaic system for southern part of 
India," Building Services Engineering Research and Technology, vol. 42, no. 2, pp. 237-248, 2021.

[19] N. Gull, S. M. Khan, M. A. Munawar et al., "Synthesis and characterization of zinc oxide $(\mathrm{ZnO})$ filled glass fiber reinforced polyester composites," Materials and Design, vol. 67, pp. 313-317, 2015.

[20] F. Anjum, N. Gull, S. M. Khan et al., "Mechanical, thermal, and microscopic profile of novel glass fiber-reinforced polyester composites as a function of barium sulfate loading," Advances in Polymer Technology, vol. 37, no. 3, pp. 929-936, 2018.

[21] H. Aghamohammadi, R. Eslami-Farsani, and A. Tcharkhtchi, "The effect of multi-walled carbon nanotubes on the mechanical behavior of basalt fibers metal laminates: an experimental study," International Journal of Adhesion and Adhesives, vol. 98, p. 102538, 2020.

[22] R. Eslami-Farsani, H. Aghamohammadi, S. M. R. Khalili, H. Ebrahimnezhad-Khaljiri, and H. Jalali, "Recent trend in developing advanced fiber metal laminates reinforced with nanoparticles: a review study," Journal of Industrial Textiles, no. article 1528083720947106, 2020.

[23] R. Keshavarz, H. Aghamohammadi, and R. Eslami-Farsani, "The effect of graphene nanoplatelets on the flexural properties of fiber metal laminates under marine environmental conditions," International Journal of Adhesion and Adhesives, vol. 103, p. 102709, 2020.

[24] S. Senthilkumar, A. Karthick, R. Madavan et al., "Optimization of transformer oil blended with natural ester oils using Taguchi- based grey relational analysis," Fuel, vol. 288, article 119629, 2021.

[25] X. Liu, J. Guo, W. Tang et al., "Enhancing the flame retardancy of thermoplastic polyurethane by introducing montmorillonite nanosheets modified with phosphorylated chitosan," Composites Part A, Applied Science and Manufacturing, vol. 119, pp. 291-298, 2019.

[26] Z. Huang and Z. Wang, "Synthesis of a copper hydroxystannate modified graphene oxide nanohybrid and its high performance in flexible polyvinyl chloride with simultaneously improved flame retardancy, smoke suppression and mechanical properties," Polymer Degradation and Stability, vol. 183, article 109425, 2021.

[27] Z. Ding, J. Li, W. Xin, G. Zhang, and Y. Luo, "Low gloss waterborne polyurethane coatings with anti-dripping and flame retardancy via montmorillonite nanosheets," Progress in Organic Coatings, vol. 136, p. 105273, 2019.

[28] V. Kavimani, K. Soorya Prakash, T. Thankachan, and R. Udayakumar, "Synergistic improvement of epoxy derived polymer composites reinforced with graphene oxide (GO) plus titanium di oxide(TiO2)," Composites Part B, Engineering, vol. 191, p. 107911, 2020.

[29] S. U. Khan, K. Iqbal, A. Munir, and J.-K. Kim, "Quasi-static and impact fracture behaviors of CFRPs with nanoclay-filled epoxy matrix," Composites Part A, Applied Science and Manufacturing, vol. 42, no. 3, pp. 253-264, 2011.

[30] N. Jamali, H. Khosravi, A. Rezvani, and E. Tohidlou, "Mechanical properties of multiscale graphene oxide/basalt fiber/epoxy composites," Fibers and Polymers, vol. 20, no. 1, pp. 138-146, 2019.

[31] C. Y. Lee, J.-H. Bae, T.-Y. Kim, S.-H. Chang, and S. Y. Kim, "Using silane-functionalized graphene oxides for enhancing the interfacial bonding strength of carbon/epoxy composites," Composites Part A, Applied Science and Manufacturing, vol. 75, pp. 11-17, 2015.
[32] A. Feiz and H. Khosravi, "Multiscale composites based on a nanoclay-enhanced matrix and E-glass chopped strand mat," Journal of Reinforced Plastics and Composites, vol. 38, no. 13, pp. 591-600, 2019.

[33] M. Bulut, "Mechanical characterization of basalt/epoxy composite laminates containing graphene nanopellets," Composites Part B, Engineering, vol. 122, pp. 71-78, 2017.

[34] D. Toorchi, E. Tohidlou, and H. Khosravi, "Enhanced flexural and tribological properties of basalt fiber-epoxy composite using nano-zirconia/graphene oxide hybrid system," Journal of Industrial Textiles, no. article 1528083720920573, 2020.

[35] M. Qiu, D. Wang, L. Zhang, M. Li, M. Liu, and S. Fu, "Electrochemical exfoliation of water-dispersible graphene from graphite towards reinforcing the mechanical and flameretardant properties of poly (vinyl alcohol) composites," Materials Chemistry and Physics, vol. 254, p. 123430, 2020.

[36] Y. Yao, S. Jin, X. Ma et al., "Graphene-containing flexible polyurethane porous composites with improved electromagnetic shielding and flame retardancy," Composites Science and Technology, vol. 200, p. 108457, 2020.

[37] N. Wang, H. Liu, J. Zhang, M. Zhang, Q. Fang, and D. Wang, "Synergistic effect of graphene oxide and boron-nitrogen structure on flame retardancy of natural rubber/IFR composites," Arabian Journal of Chemistry, vol. 13, no. 8, pp. 62746284, 2020.

[38] A. Karthick, M. Manokar Athikesavan, M. K. Pasupathi, N. Manoj Kumar, S. S. Chopra, and A. Ghosh, "Investigation of inorganic phase change material for a semi-transparent photovoltaic (STPV) module," Energies, vol. 13, no. 14, p. 3582, 2020.

[39] B. Yuan, A. Fan, M. Yang et al., "The effects of graphene on the flammability and fire behavior of intumescent flame retardant polypropylene composites at different flame scenarios," Polymer Degradation and Stability, vol. 143, pp. 42-56, 2017.

[40] W. Du, Y. Jin, S. Lai, L. Shi, Y. Shen, and H. Yang, "Multifunctional light-responsive graphene-based polyurethane composites with shape memory, self-healing, and flame retardancy properties," Composites Part A, Applied Science and Manufacturing, vol. 128, p. 105686, 2020.

[41] B. Stalin, M. Ravichandran, G. T. Sudha et al., "Effect of titanium diboride ceramic particles on mechanical and wear behaviour of $\mathrm{Cu}-10 \mathrm{wt} \% \mathrm{~W}$ alloy composites processed by P/M route," Vacuum, vol. 184, p. 109895, 2021.

[42] X. He, W. Zhang, and R. Yang, "The characterization of DOPO/MMT nanocompound and its effect on flame retardancy of epoxy resin," Composites Part A, Applied Science and Manufacturing, vol. 98, pp. 124-135, 2017.

[43] D. Kim, G. Mittal, M. Kim, S. Kim, and K. Yop Rhee, "Surface modification of MMT and its effect on fatigue and fracture behavior of basalt/epoxy based composites in a seawater environment," Applied Surface Science, vol. 473, pp. 55-58, 2019.

[44] V. S. Souza, O. Bianchi, M. F. S. Lima, and R. S. Mauler, "Morphological, thermomechanical and thermal behavior of epoxy/MMT nanocomposites," Journal of Non-Crystalline Solids, vol. 400, pp. 58-66, 2014.

[45] N. T. Kamar, M. M. Hossain, A. Khomenko, M. Haq, L. T. Drzal, and A. Loos, "Interlaminar reinforcement of glass fiber/epoxy composites with graphene nanoplatelets," Composites Part A, Applied Science and Manufacturing, vol. 70, pp. 82-92, 2015. 
[46] M. Naeem, H.-C. Kuan, A. Michelmore et al., "A new method for preparation of functionalized graphene and its epoxy nanocomposites," Composites Part B, Engineering, vol. 196, article 108096, 2020.

[47] V. Vyas, T. Kaur, and A. Thirugnanam, "Chitosan composite three dimensional macrospheric scaffolds for bone tissue engineering," International Journal of Biological Macromolecules, vol. 104, Pt B, pp. 1946-1954, 2017.

[48] A. Kumar, A. M. Sadanandhan, and S. L. Jain, "Silver doped reduced graphene oxide as a promising plasmonic photocatalyst for oxidative coupling of benzylamines under visible light irradiation," New Journal of Chemistry, vol. 43, no. 23, pp. 9116-9122, 2019.

[49] N. Hu, Z. Yang, Y. Wang et al., "Ultrafast and sensitive room temperature NH3 gas sensors based on chemically reduced graphene oxide," Nanotechnology, vol. 25, no. 2, article 25502, p. 025502, 2014.

[50] G. Bharath, B. S. Latha, E. H. Alsharaeh, P. Prakash, and N. Ponpandian, "Enhanced hydroxyapatite nanorods formation on graphene oxide nanocomposite as a potential candidate for protein adsorption, $\mathrm{pH}$ controlled release and an effective drug delivery platform for cancer therapy," Analytical Methods, vol. 9, no. 2, pp. 240-252, 2017.

[51] R. K. Prusty, S. K. Ghosh, D. K. Rathore, and B. C. Ray, "Reinforcement effect of graphene oxide in glass fibre/epoxy composites at in-situ elevated temperature environments: an emphasis on graphene oxide content," Composites Part A, Applied Science and Manufacturing, vol. 95, pp. 40-53, 2017.

[52] T. A. Nguyen, Q. T. Nguyen, and T. P. Bach, "Mechanical properties and flame retardancy of epoxy resin/nanoclay/multiwalled carbon nanotube nanocomposites," Journal of Chemistry, vol. 2019, 9 pages, 2019.

[53] S. Liu, Z. Fang, H. Yan, V. S. Chevali, and H. Wang, "Synergistic flame retardancy effect of graphene nanosheets and traditional retardants on epoxy resin," Composites Part A, Applied Science and Manufacturing, vol. 89, pp. 26-32, 2016.

[54] M. Kamaraj, E. A. Dodson, and S. Datta, "Effect of graphene on the properties of flax fabric reinforced epoxy composites," Advanced Composite Materials, vol. 29, no. 5, pp. 443-458, 2020.

[55] W. Chen, Y. Liu, P. Liu, C. Xu, Y. Liu, and Q. Wang, "The preparation and application of a graphene-based hybrid flame retardant containing a long-chain phosphaphenanthrene," Scientific Reports, vol. 7, no. 1, article 8759, 2017. 